\title{
Modos de falar de si: a dimensão estética nas narrativas autobiográficas
}

Luciana Esmeralda Ostetto * Rosvita Kolb-Bernardes* *

http://dx.doi.org/10.1590/0103-7307201507611

\section{Resumo}

0 artigo apresenta e analisa o trabalho biográfico desenvolvido com um grupo de jovens que começava sua jornada no curso de Mestrado em Pedagogia do Teatro da Universidade de Rostock (norte da Alemanha). Inspirado na proposta de "ateliê biográfico de projeto", o trabalho procurou amplificar possibilidades nos modos de falar de si, utilizando-se de diferentes linguagens e materialidades expressivas. Pressupondo a dimensão estética, poética, dos processos de produção de narrativas autobiográficas, o convite à imaginação criadora mobilizou, no campo

* Universidade Federal Fluminense - UFF, Faculdade de Educação, Departamento SSE, Niteroi, RJ, Brasil. luesmeralda@uol.com.br

* * Universidade do Estado de Minas Gerais - UEMG, Escola Guignard, Belo Horizonte, MG, Brasil. rosvitakolb@gmail.com

Palavras-chave: ateliê biográfico, narrativas estéticas autobiográficas, danças circulares, arte, formação 


\title{
The way of talking about him/herself: the aesthetical dimension of autobiographical narratives
}

\begin{abstract}
This paper presents and analyzes the biographical work developed with a group of students who began their journey in the master course in Theater Pedagogy at the University of Rostock (Northern Germany). Inspired by the proposal of a "biographical workshop", the work followed the perspective of amplifying the possibilities of ways of talking about themselves using different languages and expressive materials. Assuming the aesthetic and poetic dimension of the production processes of autobiographical narratives, this invitation to a creative imagination mobilized - in the field of sensitivity - understanding and writing itself.
\end{abstract}

Keywords: biographical workshop, autobiographical aesthetic narrations, dancing circles 
As dimensões experienciais e formativas inerentes aos percursos de vida-formação ganham destaque na contemporaneidade, supondo o acolhimento de narrativas constituídas nas "relações entre lembranças, memórias, esquecimento e experiência, centrando no sujeito da narração as possibilidades de reinvenção das dimensões subjetivas da vida e do cotidiano, com ênfase nos testemunhos como um dos modos de narração e de atos da memória” (Souza, 2008, p. 97). Vinculando passado e presente, os discursos da memória e os modos de falar de si permitem, como nos diz Elizeu Clementino de Souza (2008), a “reconstituição da textura da vida”, marcando aspectos formativos que constituem subjetividades e identidades.

A proposta do "ateliê biográfico de projeto", tal como formulada pela pesquisadora Christine Delory-Momberger (2006), é especialmente propícia para lançar luzes sobre aquelas texturas da vida que compõem os percursos pessoais, revelando histórias que só se deixam mostrar por meio de narrativas que engendram o pensar sobre si e a tomada de consciência de si. Neste quadro, a dinâmica constitutiva do ateliê biográfico de projeto, compreendido como

um procedimento que inscreve a história de vida em uma dinâmica prospectiva que liga o passado, o presente e o futuro do sujeito e visa fazer emergir o seu projeto pessoal, considerando a dimensão do relato como construção da experiência do sujeito e da história de vida como espaço de mudança aberto ao projeto de si (Delory-Momberger, 2006, p. 359),

inspirou o trabalho desenvolvido com um grupo de estudantes do curso de Mestrado em Pedagogia do Teatro, na cidade de Rostock, situada no norte da Alemanha.

0 referido trabalho foi planejado e realizado no contexto de um projeto de colaboração firmado entre a Escola Guignard, da Universidade do Estado de Minas Gerais, e a Escola Superior de Música e Teatro de Rostock. O convênio estabelecido entre as duas instituições, cujo período de vigência compreende o intervalo de 2012 a 2016, congrega um plano de intercâmbio acadêmico-cultural, baseado nos preceitos da transculturalidade e da interdisciplinaridade. Focado no diálogo sobre questões teórico-metodológicas advindas do campo constituído na interface educação/arte, tal convênio de cooperação internacional visa ampliar as experiências e a compreensão dos processos culturais e pedagógicos envolvidos na formação de professores de Arte. Voltadas, sobretudo, às áreas de Artes Visuais e Teatro, no âmbito da graduação e da pós-graduação, as ações do projeto acordado contemplam atividades de pesqui- 
sa e viagens de estudo (com a participação de docentes e discentes), assim como a organização de seminários temáticos integradores, criações e intervenções artísticas no Brasil e na Alemanha.

A proposta específica aqui apresentada e analisada resultou do seminário temático programado e oferecido, como já mencionado, aos ingressantes no Curso de Mestrado em Pedagogia do Teatro da universidade alemã, em janeiro de 2012. Marcando a oficialização do convênio, o tema do seminário foi solicitado pelos docentes participantes do projeto naquela instituição, sendo que as atividades desenvolvidas e os conteúdos abordados estiveram referenciados nos estudos que vêm sendo desenvolvidos pelas autoras ${ }^{1}$ do presente artigo, em interlocução com o significativo volume de conhecimento produzido no campo da pesquisa (auto)biográfica.

\section{Quando o indivíduo se faz intérprete dele mesmo}

$\mathrm{O}$ ato de narrar o vivido carrega a essencialidade do poder de as pessoas se reconhecerem como sujeitos de suas próprias histórias, atribuindo sentido aos diferentes itinerários percorridos. Ao comporem narrativas sobre a vida vivida, colocam-se em posição de escuta, olham para múltiplas direções, dentro e fora de si, reportando-se ao que foram, ao que são, ao que desejam ser; ao que fizeram, ao que fazem, ao que projetam fazer. Caminhos a percorrer podem ser evidenciados no processo. Pelo trabalho da reflexão, no tramado de relações percebidas, a construção de significados em torno de novas rotas que se anunciam é potencializada.

Na apresentação de si mesmo por meio do relato, o indivíduo se faz intérprete dele mesmo: ele explicita as etapas e os campos temáticos de sua própria construção biográfica. Ele também é intérprete do mundo histórico e social que é o dele: ele constrói figuras, representações, valores ... considerando que é no relato que ele faz suas experiências de que o sujeito produz categorizações que lhe permitem apropriar-se do mundo social e nele definir seu lugar (Delory-Momberger, 2006, p. 369).

Ou seja, refletir sobre os processos de formação, parar para pensar nas experiências vividas permite um movimento singular de investi-

1. Sendo de instituições distintas, as autoras fazem parte do mesmo grupo de pesquisa. A professora Luciana Ostetto foi especialmente convidada para integrar o programa do Seminário. gação sobre os percursos pessoais; investigação que pode iluminar saberes e fazeres que constituem a pessoa e, assim, ajudam a dar visibilidade 
aos fios de histórias particulares que se entrelaçam em trajetórias reveladas no presente. Por meio do exercício da memória, a história é revisitada pelo olhar que mira o passado nas marcas do presente, oferecendo elementos para a compreensão do percurso e, dessa forma, para o desenho de novas tramas. Por meio da "reflexividade biográfica", os processos de "biografização" são ativados (Delory-Momberger, 2006, p. 369), inaugurando uma dinâmica por meio da qual o projeto de si se esboça em direção ao futuro.

Na proposta compartilhada e vivenciada com os estudantes na Alemanha, além da palavra, utilizamo-nos de outras linguagens e materialidades, sobretudo elementos da dança de roda tradicional dos povos (danças circulares) e das artes plásticas. A circularidade, a música, a dança, as cores, as formas, as tintas, as linhas, os tecidos e os diferentes suportes para a produção plástica foram utilizados para criar um espaço-tempo de narrativas (narrativas estéticas, narrativas poéticas autobiográficas) durante o qual aquele grupo pudesse repensar seus projetos acadêmicos, vislumbrando perspectivas futuras, revendo metas, traçando novos objetivos, redefinindo ou reafirmando projetos investigativos já desenhados; um espaço-tempo que validasse um processo de formação além dos saberes formais, reconhecendo como importantes os saberes da experiência.

Esse foi o norte, o foco, o objetivo geral que sustentou e conduziu o trabalho desenvolvido ao longo de três dias de intenso convívio entre duas professoras brasileiras e um grupo de oito jovens alemães e do leste europeu (com idades entre 25 e 28 anos). Assim nos aventuramos por territórios que permitiram a busca, o encontro e a narração de histórias por meio de diferentes linguagens - oralidade, escrita, dança, desenho, pintura, recorte-colagem, bordado. As palavras-chave que nos impulsionaram foram experimentação, criação, feito à mão, narração, reinvenção.

Assumindo a dinâmica do círculo como princípio (Ostetto, 2009), começamos o trabalho com o grupo de estudantes ao redor de um centro especialmente demarcado e preparado. Sentamo-nos em volta daquele centro constituído e conversamos sobre a proposta do seminário, a dinâmica e o conteúdo dos encontros. Afinal, o ponto de partida de um trabalho biográfico, tal como estávamos a propor, deve estar no acordo entre os participantes.

\section{Dança na roda: território de passagem, sensibilização para o encontro (auto)biográfico}

Como um fio que tece caminhos e delineia territórios de passagem para o desvelar de processos (auto)biográficos, a dança circular dos povos percorreu e enlaçou a jor- 
nada, ajudando a compor os tempos e os espaços da experiência projetada. Ao longo de toda a proposta vivida naqueles três dias, as danças de roda estiveram presentes em diferentes momentos, ora abrindo, ora fechando um ciclo de pensar e fazer e sentir, de experimentar e refletir, enfim.

Nas práticas de danças circulares da contemporaneidade, as raízes de um passado longínquo, ancestral, da dança dos povos de caráter comunitário e gregário, estão marcadamente presentes. Como apontou Roger Garaudy (1980), no passado os homens dançaram todos os momentos importantes da vida - do nascimento ao funeral, da guerra à paz, da plantação à colheita. Na atualidade, tal como são praticadas, as danças circulares sagradas reencontram e recuperam a dança como comunhão e transcendência, celebração e participação, encontro e reafirmação dos ciclos da vida, na tensão entre os mistérios humano e divino (Ostetto, 2006).

Na pesquisa “Educadores na roda da dança: formação-transformação” (Ostetto, 2006), a autora dá visibilidade às práticas de danças circulares, utilizando-as em uma proposta de formação de professores articulada à educação estética. Em diálogo com os dados e as informações disponibilizados pela pesquisadora, ao longo da leitura podem-se tecer significações e capturar características dessa singular modalidade de dança em grupo.

Como no passado, a dança circular acolhe a todos, uma vez que para dançar basta entrar na roda, dar as mãos e abrir-se para o encontro além da palavra. Nos passos, nos compassos, nas músicas e nas coreografias carregadas de simbolismo, o grupo descreve formas variadas no espaço. A principal e mais comum é a formação em círculo, que pode abrir-se ou fechar-se, desenhando linhas, espirais, meandros na sua movimentação. As danças de pares são também bastante comuns e lembram diretamente as tradicionais danças de roda festivas. Ao entrarmos no círculo da dança, o contato com diferentes culturas é ativado, vivenciando ritmos e gestos prenhes de significados, movendo e removendo reminiscências (Ostetto, 2006).

Por um lado, a forma circular da dança faz lembrar cantigas de roda infantis, folguedos que comumente experimentamos quando crianças. Quase de imediato, a conexão é estabelecida, e sutilmente o fio da memória é tocado. Ao mesmo tempo, seguindo a música, com ritmos e melodias de diversas partes do mundo (Grécia, Albânia, Romênia, Iugoslávia, Bulgária, Hungria, Macedônia, Israel, Escócia, Irlanda, Rússia, Índia, Brasil, por exemplo), os participantes são lançados a experiências aventureiras por territórios desconhecidos. Os gestos sugeridos em cada coreografia, 
como que configurando um ritual, convidam ao encontro com o outro (interna e externamente a cada um): de mãos dadas, o círculo formado move-se ao redor de um centro, cuidadosamente preparado.

0 centro do círculo é a manifestação. É a criação. Neste centro pode haver uma vela. $\mathrm{Eu}$, particularmente, trabalho assim. Esta vela tem a função psicológica de ser um catalisador da atenção, ao mesmo tempo em que simboliza a luz da consciência, a luz menor que está dentro do homem, a sabedoria que está envolvida na busca da harmonização com os ritmos cósmicos, pois: assim como é em cima, é embaixo [grifos do autor]. (Berni, 2002, p. 67).

Tudo converge para o centro, símbolo da fonte, da criação, da luz, o ponto comum que une a todos (Ostetto, 2009). É ao redor de um centro que a roda gira. Esse centro pode ser imaginário ou concretamente delimitado com toalhas, lenços coloridos, velas, flores, incenso e outros arranjos com objetos ou símbolos diversos.

O significado da direção empreendida em cada dança depende da tradição na qual se insere ou do simbolismo impresso pelo coreógrafo. De modo geral, compreende-se que o sentido horário é a direção do passado, e o anti-horário, do futuro. Conforme Bernhard Wosien (2000), no sentido horário estaria o fluxo das lembranças e, no sentido contrário, o fluxo do conhecimento e da iluminação.

Também a posição das mãos e dos braços carrega simbologias distintas. Antes de qualquer movimento, no ato de juntar as mãos entre si, os dançarinos formam um campo de energia que circula no grupo, pela posição das mãos: uma com a palma para baixo - simbolizando o dar, e outra para cima - simbolizando o receber. "Quando os dançarinos se ordenam num círculo, de acordo com a tradição, eles se dão as mãos. A mão direita torna-se a que recebe e a esquerda a que dá" (Wosien, 2000, p. 29).

Braços estendidos para baixo (dizemos em "V", pois é o desenho que se forma na junção dos braços de um e outro dançarino no círculo) significam a conexão com a terra; braços dobrados na altura do coração (dizemos em “W”) representam a conexão na roda, no aqui e agora; braços elevados para cima, em direção aos céus, conexão com o infinito, a força superior. Há também a posição em que os braços se cruzam em espiral, simbolizando força, unidade e eternidade (Barton, 1995, citado por Ostetto, 2009). 
Considerando as características assinaladas, nota-se que a dança circular é uma linguagem que não se limita à racionalidade dos preceitos teórico-metodológicos educacionais, em regra aprisionados à linguagem da ciência, calcada na palavra, no conceito. É um universo de conhecimento diferente, desconhecido, mais próximo da arte.

As danças circulares ligam-se, pois, àquele conjunto de práticas e saberes que foram relegados pela ciência, no seu afã de tudo classificar e controlar. Como conteúdo esquecido pelo homem moderno, condenado ao império da razão, pode ser um dos caminhos para restabelecer o contato com dimensões perdidas no mundo fundado com a modernidade, que separou pensar e fazer, cognição e afeto, razão e emoção, consciência e inconsciente, arte e ciência (0stetto, 2006, p. 213).

No âmbito de uma experiência que pretenda potencializar a narrativa (auto)biográfica, como aquela proposta no esboço de ateliê biográfico realizado e que aqui estamos analisando, a dinâmica das danças circulares apresenta-se como um contexto significativo e particularmente fecundo para ancorar o mergulho da memória. Ao chamar o corpo inteiro, no movimento que impulsiona a roda com todos os participantes, sutilmente a vivência do sensível se efetiva e abre um campo de acesso aos processos de autoconhecimento, franqueando passagem para imagens, recordações, sentimentos, estranhamento, aproximações, apreciação, que, ao longo dos encontros, podem ser amplificados, apropriados e simbolizados como matéria de genuína autobiografia (Ostetto \& Berkenbrock-Rosito, 2008).

Simbolizar é descobrir outros sentidos, ir além do conhecido, atravessar fronteiras; é fazer ligações, unir fragmentos, expandir a personalidade. Há nessa dinâmica um convite a um curioso escutar e ver as coisas de modo diferente. Não explicá-las ou, mesmo, compreendê-las, mas não negar o desconhecido e, talvez, sim, surpreender-se com o que aparece. Aí está o germe da criação (Ostetto, 2010).

As práticas com as danças circulares possibilitam o contato com conteúdos que permitem o exercício de imaginação ativa (Jung, 1991), pois, na medida em que conduzem os participantes ao encontro do desconhecido presente nas diferentes culturas, tira-os do lugar, mostra-lhes outros lugares - neles e no mundo. Ao tomar contato com símbolos e rituais de diferentes culturas, quem está na roda da dança pode atravessar o inexplicável campo do mistério que é, também, o território da criação 
(Ostetto, 2010). Como disse o poeta: “Temos que aceitar a nossa existência em toda a plenitude possível; tudo, inclusive o inaudito, deve ficar possível dentro dela. No fundo, só essa coragem nos é exigida: a de sermos corajosos em face do estranho, do maravilhoso e do inexplicável que se nos pode defrontar" (Rilke, 1998, p. 66).

Nas danças realizadas com esse específico grupo de mestrandos, algumas coreografias (como aquelas das danças gregas) nos conduziram a entrar e a sair de espirais desenhadas no espaço. Foi como entrar e sair do labirinto de memórias, constituído de luzes e de sombras, de clarezas e obscuridades. A figura do labirinto comumente representa os vários ciclos de tempo ou sequências de evolução, em que o centro indica o ponto de retorno que conecta diferentes dimensões da existência. 0 labirinto simboliza os ciclos, "o ser e desvanecer na natureza, o caminho de vida e morte do homem, a condensação de energia em matéria e sua dissolução, a dinâmica polar do tempo e da ausência de tempo" (Wosien, 2004, p. 20).

Referindo-se à experiência de percorrer o caminho em labirinto, a analista junguiana Jean Bolen (1996) nos diz: "O padrão que consiste em entrar, chegar ao centro e sair é ... um mapa do processo psicológico: mudança, encontro e integração" (p. 150). No caminho da vida almejamos o centro, mas há obstáculos para alcançá-lo. Para superar as dificuldades que impedem o encontro com o centro, há sacrifício, que equivale a mudanças necessárias para prosseguir. Tendo chegado lá, pode acontecer o encontro de transformação e, ao retornar dele, há a tarefa de renovação, de integração.

Para entrar no labirinto, houve antes um tempo de preparação: lado a lado, mãos dadas, círculo fechado para a apresentação que preparou o campo para o exercício da memória voluntária, sutilmente provocada pelo canto primitivo e pela melodia que envolvia a todos naquele movimento inicial.

\section{Das memórias dançadas às relíquias da vida de cada um}

A dança inaugural, chamada "Canto das ancestrais", conduziu a roda para o passado, girando no sentido horário, rumo às lembranças que habitavam em cada ser, em direção aos tempos, aos espaços e à linhagem materna, constitutivos da história de cada um.

Envolvidos pelo canto e pela dança que povoou a sala, após o último passo da coreografia fez-se silêncio. A viagem de retorno fora profunda. Depois, as vozes de cada um romperam aquele silêncio-busca, trazendo de dentro dele algumas informa- 
ções: seu nome, idade, cidade de nascimento. 0 canto que sustentava a dança fazia referência à ancestralidade feminina e, conectados com essa referência, a linhagem materna de cada um foi chamada à roda, momento em que o nome da mãe e o nome da avó foram pronunciados, constituindo um campo de significação comum, através do qual seguiríamos trançando memórias.

A ação de rememorar, provocada pelas perguntas-guias formuladas - de onde viemos, quem nos trouxe à luz, que marcas estão em mim, a quem devo ou preciso dizer alguma coisa sobre o que fui e sobre o que me tornei? -, desencadeou a proposição de narrar-se a partir do reencontro com seu passado: a primeira escrita, feito um bilhete, uma carta. Da palavra marcada no papel, seguimos com a confecção de um relicário, um objeto simbólico, de pano bordado e costurado, para recolher e abrigar aquelas palavras primeiras de testemunhos carregados de conteúdos pessoais. Relicário que, presente e utilizado por diferentes povos e tradições ao longo da história da humanidade, ganha nas religiões de matrizes africanas a denominação de patuá (Kolb-Bernardes, 2010).

A palavra "relicário" é originária do latim e pode significar caixa, cofre, lugar próprio para guardar relíquias. Um relicário é continente e, nesse sentido, é um lugar peculiar e especial para conter coisas preciosas, de valor, de estima e apreço: relíquias; pode ser um saquinho, uma bolsinha ou um medalhão. No caso do campo simbólico construído com o grupo, no contexto das ações autobiográficas pretendidas, os relicários, costurados pelas próprias mãos dos participantes, guardariam reminiscências das histórias de vida recolhidas da memória provocada e em cuja escrita estariam reconhecendo e honrando as marcas do caminho que foram trilhando para tornarem-se o que são.

Dessa forma, o passado vivido fazia-se potência pela ação do rememorar, compreendido "como opção de questionamento das relações e sensibilidades sociais existentes também no presente, uma busca atenciosa relativa aos rumos a serem construídos no futuro" (Galzerani, 2005, citada por Kolb-Bernardes, 2011, p. 132). $\mathrm{Na}$ proposta de composições expressivas com diferentes materiais e linguagens, o passado-memória fluía e chegava ao presente para ser ressignificado e, por meio da reflexão, projetar-se, esboçando o porvir.

Dentro do patuá foi guardado o segredo de cada um, “segredos do coração” (Kolb-Bernardes, 2010) que se anunciaram na escrita primeira realizada depois da dança e foram recolhidos, pois ainda não era o momento para a partilha das histórias. 
Considerado como um trabalho exploratório, a costura do relicário para guardar a carta-bilhete escrita com o conteúdo da lembrança, envolvida no sentimento e no pensamento, configurou-se como aquecimento, acendendo a chama da memória, provocando todos os sentidos para a sequência em andamento. Na força e na beleza do feito à mão, aos poucos se revelava a inteireza de ser.

Foi especialmente significativo olhar aqueles jovens, homens e mulheres do século XXI, vindos de diferentes regiões, associados ao redor de tecidos, linhas, agulhas, fazendo escolhas, a tramar o seu relicário. O clima era de introspecção, cada qual voltado para si mesmo, atenciosamente buscando. Percebia-se que era uma novidade para o grupo mexer e compor com aqueles materiais e, tal qual crianças que se entregam à curiosidade, à aventura, à descoberta de novas composições, foi possível testemunhar uma entrega genuína, uma alegria visível na experiência de fazer à mão. Uma preciosidade, deveras.

Depois de costurados, os patuás foram colocados no centro da roda e dançamos ao redor daquelas produções que guardavam relíquias históricas particulares, os segredos de cada um, que abrigavam conteúdos pessoais que continuariam a acompanhar os participantes nas próximas etapas do ateliê. Nesse momento, a dança realizada foi "Menoussis - Perpetual motion", uma dança grega introspectiva, também conhecida por "Roda da vida", cujos passos coreográficos fazem menção ao fluxo da vida que gira continuamente, movimentando passado-presente-futuro. Na suavidade da dança, afirma-se o princípio de que o rio da vida corre para o futuro, mas o passado faz parte dele e não pode ser esquecido; ao contrário, é necessário que sejam incorporados na consciência conteúdos desse passado, para ressignificá-los a partir da realidade presente e então seguir com inteireza, perspectivando o futuro.

Dessa forma, na costura do relicário, na dança e na reflexão sobre o movimento contínuo da vida, marcamos o início do processo. Com as mãos, o corpo e o coração. Artesanalmente. Suavemente. Inteiramente.

\section{Até chegar à palavra: processos expressivos, experiência estética}

0 trabalho autobiográfico pressupõe a utilização de uma linguagem racional, mas que comporta uma dimensão imaginária, como disse Josso (2004), uma vez que não se trata de uma apropriação pura e absoluta do passado vivido, mas, sim, de uma releitura do passado. Assim, podemos afirmar também que a utilização de diferen- 
tes suportes e materialidades expressivos potencializa o caminho que conduz a tal releitura do vivido; caminhos que, pelo convite à imaginação criadora, acolhem sentidos e significados, como que sinalizando indícios da história que cada um fez e das histórias que fizeram a cada um nas suas trajetórias existenciais, intensificando a compreensão no campo da sensibilidade (Ostetto \& Berkenbrock-Rosito, 2008).

Trata-se de assinalar a presença e a importância da dimensão estética nos processos de construção das narrativas autobiográficas, onde diferentes linguagens e recursos expressivos potencializam as múltiplas interfaces do conhecimento de si, na relação sentimento-pensamento com e sobre o mundo (interno e externo a cada um), provocando diálogos de inteireza e intensidade vividas; onde o sensível e o inteligível são acionados, transformando saberes. A fruição (como no caso da participação na roda da dança), assim como o fazer criador (nesse primeiro momento, na costura do patuá), a apreciação ativa e a avaliação crítica sobre as produções narrativas estiveram marcando a experiência aqui discutida, ampliando modos de ver e compreender o vivido.

A experiência estética coloca a cognição em permanente desconstrução e reconstrução, pela vulnerabilidade aos acontecimentos, estados de espírito, relações com a cultura, saberes múltiplos vindos do corpo e de abstrações, além do que a mente elabora a partir de paisagens do corpo, do ambiente, da memória e da ficção (Meira, 2007, p. 32).

Nesse contexto, no segundo dia, o conteúdo rememorado foi amplificado com a composição de um "mapa-rio da vida”, criado a partir de gotas de anilina, pingadas e deixadas escorrer na superfície de papel canson (formato A3). Nas bordas da imagem que surgiu, indícios de um rio que corre e percorre diferentes direções, traçando um percurso de idas e vindas, entradas e saídas, contenções e expansões. Nas marcas particulares que se formaram em cada papel, os participantes escreveram seus percursos de vida, assinalando os acontecimentos mais significativos desde a nascente.

As histórias contadas ao longo daquele rio que corria no papel, evocando passagens e eventos da vida de cada um, foram, então, partilhadas na roda: todos escutaram as narrativas de todos no grupo, cada qual apresentando o seu "mapa-rio" histórico. Na exposição, a palavra de cada um foi pronunciada na roda, sendo acolhida e também questionada pelos ouvintes.

As imagens que surgiram falavam de dificuldades, leveza, acolhimento, amor, be- 
leza, sabedoria, alegria, amargura e doçura, simplicidade, aventuras, viagens, amizades, afetos, infância, família, desejos. Deixavam entrever percursos trilhados em redemoinhos, constituídos de encontros e desencontros. Caminhos cruzados, mudanças, dúvidas, escolhas, medo, transformações, experiências múltiplas. Estampava-se, pois, a identidade nos percursos individuais, potencializando a lembrança em apreensões e compreensões dos processos de cada um. Como afirmou Thompson (1998, citado por Souza, 2008), "recordar a própria vida é fundamental para nosso sentimento de identidade; continuar lidando com essa lembrança pode fortalecer, ou recapturar, a autoconfiança” (p. 97).

Nesse movimento entre recordar, estampar o caminho percorrido, falar da experiência do vivido com os elementos capturados nos atos de memória, pudemos perceber que as narrativas compartilhadas no discurso construído a partir da leitura do "mapa-rio da vida" estavam relacionadas "ao mesmo tempo, aos projetos de que podem constituir a marca no passado dos participantes e àqueles que podem desenhar os contornos para o futuro" (Delory-Momberger, 2006, p. 367). Sendo que o passado não está descolado do presente, voltar a ele para visualizar focos de interesse circunstanciais ou temas que persistem ao longo da jornada abre possibilidades para compreendê-lo e, dessa forma, indicar perspectivas para o planejamento de projetos que se relacionam com nossa autobiografia.

No terceiro e último dia, ao "mapa-rio da vida" foram adicionadas fotos da infância e, com a utilização de tintas, lápis de cor, tesouras, cola, papéis coloridos, revistas, ele foi redimensionado plasticamente, tendo como guias as questões: Que dança posso fazer para projetar-me, lançar-me para frente? Para onde vou daqui? Que projeto posso alinhavar a partir das histórias mapeadas?

Na roda de partilha, os mapas, então recriados com a utilização de materiais e técnicas artísticas, foram apresentados. Olhar fatos, tempos e espaços vividos, mapeados e ampliados na produção plástica, permitiu aprofundar a reflexão sobre as histórias e as narrativas de si que vinham sendo construídas desde o primeiro dia.

Ao longo do processo, tendo como suporte alguns princípios do ateliê biográfico, as memórias revisitadas foram amplificadas por meio de gestos, vozes e imagens e, na visibilidade inaugurada, entregaram-se a novos significados para cada pessoa. Trechos das narrativas escritas pelos participantes oferecem exemplos da reflexão empreendida em direção ao projeto de si. Podemos capturar, das narrativas, aquele "ato de passagem [grifo da autora] pelo qual o narrador retoma, de acordo com 
os processos associativos, os espaços e os tempos esparsos e polimorfos de sua existência em um espaço-tempo construído e unificado", como nos indicara Delory-Momberger (2006, p. 362).

É uma boa coisa iniciar o ano olhando para o passado para pintar seu futuro. Nestes dias trabalhamos passado-presente-futuro de forma simbólica: dançamos, trabalhamos plasticamente. Para mim significou olhar para trás e ver o que sei, o que sou e o que fui. Assim posso pensar no futuro. Pude olhar para o futuro e perceber quanto é difícil conciliar os diferentes sonhos nesse caminho - um caminho de diferentes vias e direções que fui construindo no mapa-rio da vida. A imagem que apareceu me mostrou que eu tenho outro sonho. (A.)

Olho para a composição que surgiu, entre escritas, tintas e recortes: está tudo em aberto! Há milhões de coisas para fazer, há inúmeras possibilidades... mas ainda não sei para onde ir. Parece uma questão da minha faixa etária: temos muitas opções, podemos fazer tudo, se assim o desejarmos. Mas ao mesmo tempo, esse horizonte aberto, carregado de possibilidades, traz muitas dificuldades. Quero estudar, mas trabalhar é preciso. Viajar pelo mundo inteiro, mas ter uma familia, filhos. (K.)

Saí da casa de meus pais e vim para Rostock. Foi minha primeira saída, estou em plena experiência de viver sozinho. Compreendi uma contradição: gosto de ficar só, mas gosto de estar com os outros. Busco o equilíbrio. Ao compor minha história, identifiquei alguns medos: medo de não ser respeitado (econômica e academicamente) pelas minhas escolhas, principalmente por ter escolhido o teatro; medo de ter ou não ter trabalho. Comecei a pensar na velhice: terei tranquilidade? ... A linha dos amigos é central no meu mapa. É preciso cuidar das amizades, cultivar os afetos. (F.)

Minha construção (plástica) está dizendo: estou vivendo o final de um começo... Incrível perceber quantas vezes pensamos uma coisa e nos acontece outra! Parece-me que os acontecimentos marcantes são imprevisíveis. Nunca havia pensado na imagem que surgiu: quem acabou com a minha infância? (J.)

Leio na imagem produzida: o pássaro voa para a liberdade. E é assim que me vejo: gosto de viajar, estar livre. Alimento minha energia pessoal com o silêncio. Neste percurso, olhei 
com amor para a minha criança. Quero mantê-la viva dentro de mim, para sempre. E a profissão? Seria muito bom poder juntar tudo isso, toda a vida, intensa, com os fazeres profissionais. É um desafio envelhecer com saúde. (C.)

A escrita de si, mediada por atos de memória que, no caso da presente experiência, foram deflagrados na roda da dança, na costura e no bordado, na produção plástica, reafirma que o mergulho na história vivida, para encontrar e revelar imagens que falam dos processos de constituição das subjetividades, com suas marcas e texturas singulares, pode ser potencializado quando mobilizado no campo da sensibilidade. Vê-se que, nas narrativas dos corpos-pensantes-sensíveis, integrando dimensões éticas, estéticas e políticas, sonhos e projetos são permeados pela leitura do contexto em que as pessoas, sujeitos das histórias, estão inseridas, pela análise das possibilidades e dos limites de viver em uma sociedade competitiva, que pouco valoriza profissões definidas fora do âmbito da normatividade, como aquelas de matrizes artísticas, como o teatro. Trabalho e família, público e privado, desejos e realidade são conteúdos revelados e confrontados nas imagens criadas. O fazer de corpo inteiro, articulado no pensamento que expande a consciência, permite produzir novos conhecimentos de si, ampliando os sentidos de ser humano na contemporaneidade e, no caso daqueles jovens, de ser profissional, mudando, de certa forma, sua condição existencial: deixar de ser estudante.

Se "o ato de narrar experiências existenciais e profissionais, devidamente mediado, permite transformar saberes implícitos em conhecimento (pesquisa) e promover, nesse intervalo, a reinvenção de si (formação)" (Passeggi, 2010, p.115), na experiência construída no decorrer dos três dias de trabalho biográfico cada participante pôde aproximar-se e distanciar-se de si mesmo, lançando luzes sobre diferentes tempos e espaços de sua existência, para, no tempo presente, (re)significá-los. Nesse processo de busca e reflexão sobre os percursos de formação, saberes e fazeres sensíveis foram acionados na produção das narrativas autobiográficas.

A utilização de recursos e materiais expressivos diversos franqueou a abertura dos sentidos, mobilizando cabeça e coração, provocando cognição e afeto: os encontros que constituíram e constituem cada um puderam tornar-se visíveis em cores, formas, texturas, imagens composicionais, enfim. Na experiência estética oportunizada, os estudantes colocaram-se em conexão direta com a vida, com o outro. Observamos que foi importante e até decisivo o contato com diferentes materiais, pois com eles e 
a partir deles interpelaram os indícios que se anunciaram nas imagens, deslocaram as suas narrativas. As ideias já construídas de si puderam ser questionadas e ampliadas, de maneira a redesenharem as linhas que conduziam à leitura, quiçá compreensão, dos percursos vividos.

Depois da dança, a matéria manipulada, com todas as suas propriedades e seus estímulos, ainda puxava e envolvia a memória, visibilizando-a num processo inquietante de criação. Um processo de criação desencadeado pelo ato de experimentar, de observar, de compor, de recompor. De entregar-se! De recolhimento e silêncio profundo, para alguns; e, para outros, de barulho e expansividade, mas todos ocupando o espaço, cultivando espaços, para dizer, comunicar, compreender... Para encontrar-se e se lançar à frente.

Acompanhar este grupo de estudantes na sua experimentação (visual, estética, expressiva) autobiográfica nos apontou que o mais importante, em trabalhos como o proposto, não é a construção da representação imagética a partir do ato de rememorar, tomando-a, simplesmente, como obra artístico-expressiva, que se oferece à análise e à interpretação. A essencialidade reside em apontar como se pode dar forma e trazer à luz uma poética alojada nos sentimentos. A potência da imagem interpela, mostra, revira, contradiz, chama para novos significados, sem necessariamente defini-los. Diríamos, a exemplo dos processos artísticos, que as narrativas visuais podem conduzir seu autor lá onde não imaginaria ir, lá onde as palavras ainda não penetraram para nomeá-lo. 


\section{Referências bibliográficas}

Berni, L. E. (2002). Danças circulares sagradas: uma técnica de meditação ativa. In R. Ramos (Org.). Danças circulares sagradas: uma proposta de educação e de cura (pp.55-71). São Paulo: TRIOM.

Bolen, J. S. (1996). O caminho de Avalon: os mistérios femininos e a busca do Santo Graal. Rio de Janeiro: Rosa dos Tempos.

Delory-Momberger, C. (2006). Formação e socialização: os ateliês biográficos de projetos. Educação e Pesquisa, 32(2), 359-371.

Garaudy, R. (1980). Dançar a vida. Rio de Janeiro: Nova Fronteira.

Josso, M. C. (2004). Experiências de vida e formação. São Paulo: Cortez.

Jung, C. G. (1991). O espírito na arte e na ciência (3 ${ }^{\underline{a}}$ ed.). Petrópolis: Vozes.

Kolb-Bernardes, R. (2010). Segredos do coração: a escola como espaço para o olhar sensível. Caderno CEDES 30(80), 72-83.

Kolb-Bernardes, R. (2011). Tornar visíveis práticas invisíveis de professoras de arte. Tese de doutorado em Educação, Faculdade de Educação. Universidade Estadual de Campinas, Campinas, SP, Brasil.

Meira, M. R. (2007). Filosofia da criação: reflexões sobre o sentido do sensível. Porto Alegre: Mediação.

Ostetto, L. E. (2006). Educadores na roda da dança: formação-transformação. Tese de Doutorado, Faculdade de Educação, Universidade Estadual de Campinas, Campinas, SP, Brasil.

Ostetto, L. E. (2009). Na dança e na educação: o círculo como princípio. Educação e Pesquisa, 35(1), 177-193.

Ostetto, L. E. (2010). Para encantar, é preciso encantar-se: danças circulares na formação de professores. Caderno CEDES, 30(80), 40-55.

Ostetto, L. E., \& Berkenbrock-Rosito, M. M. (2008). Histórias tecidas na roda da dança. In M.C Passeggi, \& E. C. de Souza (Orgs.), (Auto) Biografia: formação, territórios e saberes (pp.273-283). Natal, RN: EDUFRN; São Paulo: Paulus.

Passeggi, M. C. (2010). Narrar é humano! Autobiografar é um processo civilizatório. In M. C. Passeggi, \& V. B. SILVA, (Orgs.), Invenções de vidas, compreensão de itinerários e alternativas de formação (pp.103-130). São Paulo: Cultura Acadêmica.

Rilke, R. M. (1998). Cartas a um jovem poeta (29ae ed). São Paulo: Globo. 
Souza, E. C. de. (2008). Modos de narração e discursos da memória: biografização, experiências e formação. In M. C. Passeggi, \& E. C. de Souza (Orgs.), (Auto) Biografia: formação, territórios e saberes (pp.85-101). Natal, RN: EDUFRN; São Paulo: Paulus.

Wosien, B. (2000). Dança: um caminho para a totalidade. São Paulo: TRIOM.

Wosien, M-G. (2004). Dança: símbolos em movimento. São Paulo: Anhembi Morumbi.

Submetido à avaliação em 26 de setembro de 2013; aprovado para publicação em 31 de julho de 2014. 